\title{
What's Eating You? Culex Mosquitoes and West Nile Virus
}

Marissa Lobl, BS; Taylor Kay Thieman, BS; Dillon Clarey, MD; Shauna Higgins, MD; Ryan M. Trowbridge, MD, MS, MA; Angela Hewlett, MD; Ashley Wysong, MD, MS

\section{PRACTICE POINTS}

- Dermatologists should be aware of the most common rash associated with West Nile virus (WNV), which is a nonspecific maculopapular rash appearing on the trunk and extremities around 5 days after the onset of fever, fatigue, and other nonspecific symptoms.

- Rash may serve as a prognostic indicator for improved outcomes in WNV due to its association with decreased risk of encephalitis and death.

- An IgM enzyme-linked immunosorbent assay for WNV initially may yield false-negative results, as the development of detectable antibodies against the virus may take up to 8 days after symptom onset.
West Nile virus (WNV) commonly presents cutaneously as a maculopapular rash on the trunk and extremities that most often appears around the time of defervescence and may serve as a positive prognostic indicator. Several laboratory tests can aid in diagnosis of WNV, including an IgM enzyme-linked immunosorbent assay (ELISA), but an antibody response may not be detectable for up to 8 days after symptom onset. Taking a comprehensive history in any patient presenting with a generalized maculopapular rash, fever, nonspecific symptoms, or neurologic changes can aid the astute dermatologist in promptly recognizing the possibility of WNV.

Cutis. 2021;107:244-247.

\section{What is West Nile virus? How is it contracted, and who can become infected?}

West Nile virus (WNV) is a single-stranded RNA virus of the Flaviviridae family and Flavivirus genus, a lineage that also includes the yellow fever, dengue, Zika, Japanese encephalitis, and Saint Louis encephalitis viruses. ${ }^{1}$ Birds serve as the reservoir hosts of $\mathrm{WNV}$, and mosquitoes acquire the virus during feeding. ${ }^{2}$ West Nile virus then is transmitted to humans primarily by bites from Culex mosquitoes, which are especially prevalent in wooded areas during peak mosquito season (summer through early fall in North America). ${ }^{1}$ Mosquitoes also can infect horses; however, humans and horses are dead-end hosts, meaning they do not pass the virus on to other biting mosquitoes. ${ }^{3}$ There also have been rare reports of transmission of WNV through blood and donation as well as mother-to-baby transmission. ${ }^{2}$

\section{What is the epidemiology of WNV in the United States?}

Since the introduction of WNV to the United States in 1999, it has become an important public health concern, with 48,183 cases and 2163 deaths reported since 1999. 2,3 In 2018, Nebraska had the highest number of cases of WNV ( $\mathrm{n}=251)$, followed by California $(n=217)$, North Dakota $(n=204)$, Illinois $(n=176)$, and South Dakota $(n=169){ }^{3}$ West Nile virus is endemic to all 48 contiguous states and Canada, though the Great Plains region is especially affected by WNV due

Ms. Lobl, Ms. Thieman, and Drs. Clarey, Hewlett, and Wysong are from the University of Nebraska Medical Center, Omaha. Ms. Lobl, Ms. Thieman, and Drs. Clarey and Wysong are from the Department of Dermatology, and Dr. Hewlett is from the Division of Infectious Diseases. Dr. Higgins is from the Department of Dermatology, University of Southern California, Los Angeles. Dr. Trowbridge is from CHI Health, Omaha.

Ms. Lobl, Ms. Thieman, and Drs. Clarey, Higgins, Trowbridge, and Hewlett report no conflict of interest. Dr. Wysong serves as a Research Principal Investigator for Castle Biosciences.

Correspondence: Ashley Wysong, MD, MS, 985645 Nebraska Medical Center, Omaha, NE 68198 (Ashley.wysong@unmc.edu).

doi:10.12788/cutis.0251 
to several factors, such as a greater percentage of rural land, forests, and irrigated areas. ${ }^{4}$ The Great Plains region also has been thought to be an ecological niche for a more virulent species (Culex tarsalis) compared to other regions in the United States. ${ }^{5}$

The annual incidence of WNV in the United States peaked in 2003 at 9862 cases (up from 62 cases in 1999), then declined gradually until 2008 to 2011, during which the incidence was stable at 700 to 1100 new cases per year. However, there was a resurgence of cases $(n=5674)$ in 2012 that steadied at around 2200 cases annually in subsequent years. ${ }^{6}$ Although there likely are several factors affecting WNV incidence trends in the United States, interannual changes in temperature and precipitation have been described. An increased mean annual temperature (from September through October, the end of peak mosquito season) and an increased temperature in winter months (from January through March, prior to peak mosquito season) have both been associated with an increased incidence of WNV. ${ }^{7}$ An increased temperature is thought to increase population numbers of mosquitoes both by increasing reproductive rates and creating ideal breeding environments via pooled water areas. ${ }^{8}$ Depending on the region, both above average and below average precipitation levels in the United States can increase WNV incidence the following year. ${ }^{7,9}$

\section{What are the signs and symptoms of WNV infection?}

Up to $80 \%$ of those infected with WNV are asymptomatic. ${ }^{3}$ After an incubation period of roughly 2 to 14 days, the remaining 20\% may develop symptoms of West Nile fever (WNF), typically a self-limited illness that consists of 3 to 10 days of nonspecific symptoms such as fever, headache, fatigue, muscle pain and/or weakness, eye pain, gastrointestinal tract upset, and a macular rash that usually presents on the trunk or extremities. ${ }^{1,3}$ Less than $1 \%$ of patients affected by WNV develop neuroinvasive disease, including meningitis, encephalitis, and/or acute flaccid paralysis. ${ }^{10}$ West Nile virus neuroinvasive disease can cause permanent neurologic sequelae such as muscle weakness, confusion, memory loss, and fatigue; it carries a mortality rate of $10 \%$ to $30 \%$, which is mainly dependent on older age and immunosuppression status. ${ }^{1,10}$

\section{What is the reported spectrum of cutaneous findings in WNV?}

Of the roughly $20 \%$ of patients infected with WNV that develop WNF, approximately $25 \%$ to $50 \%$ will develop an associated rash. ${ }^{1}$ It most commonly is described as a morbilliform or maculopapular rash located on the chest, back, and arms, usually sparing the palms and soles, though 1 case report noted involvement with these areas (Figure). ${ }^{11,12}$ It typically appears 5 days after symptom onset, can be associated with defervescence, and lasts less than a week. ${ }^{1,13}$ Pruritus and dysesthesia are sometimes present. ${ }^{13}$ Other rare presentations that have been reported include an ill-defined pseudovesicular rash with erythematous papules on the palms and pink, scaly, psoriasiform papules on the feet and thighs, as well as neuroinvasive WNV leading to purpura fulminans. ${ }^{14,15} \mathrm{~A}$ diffuse, erythematous, petechial rash on the face, neck, trunk, and extremities was reported in a pediatric patient, but there have been no reports of a petechial rash associated with WNV in adult patients. ${ }^{16}$ These findings suggest some potential variability in the presentation of the WNV rash.

\section{What role does the presence of rash play diagnostically and prognostically?}

The rash of WNV has been implicated as a potential prognostic factor in predicting more favorable outcomes. ${ }^{17}$ Using 2002 data from the Illinois Department of Public Health and 2003 data from the Colorado Department of Public Health, Huhn and Dworkin ${ }^{17}$ found the ageadjusted risk of encephalitis and death to be decreased in WNV patients with a rash (relative risk, $0.44 ; 95 \%$ CI, 0.21-0.92). The reasons for this are not definitively known, but we hypothesize that the rash may prompt patients to seek earlier medical attention or indicate a more robust immune response. Additionally, a rash in WNV more commonly is seen in younger patients, whereas WNV neuroinvasive disease is more common in older patients, who also tend to have worse outcomes. ${ }^{10}$ One study found rash to be the only symptom that demonstrated a significant association with seropositivity (overall risk $=6.35 ; P<.05 ; 95 \% \mathrm{CI}, 3.75-10.80$ ) by multivariate analysis. ${ }^{18}$

\section{How is WNV diagnosed? What are the downsides to WNV testing?}

Given that the presenting symptoms of WNV and WNF are nonspecific, it becomes challenging to arrive at the diagnosis based solely on physical examination. As

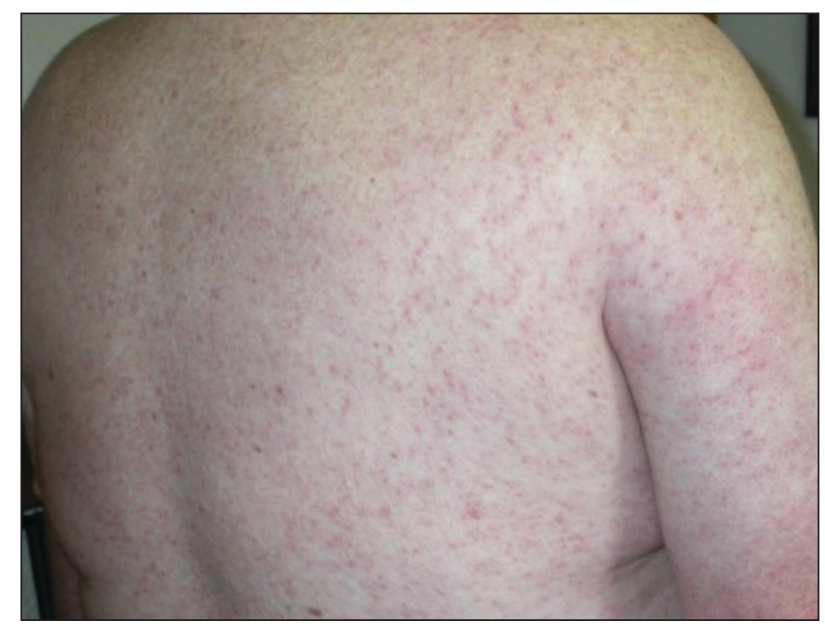

Maculopapular rash in a patient with West Nile virus distributed over the upper back and posterior arm. Reproduced with permission from Sejvar, ${ }^{12}$ Viruses; published by MDPI, 2014. 
such, the patient's clinical and epidemiologic history, such as timing, pattern, and appearance of the rash or recent history of mosquito bites, is key to arriving at the correct diagnosis. With clinical suspicion, possible diagnostic tests include an IgM enzyme-linked immunosorbent assay (ELISA) for WNV, a plaque reduction neutralization test (PNRT), and blood polymerase chain reaction (PCR).

An ELISA is a confirmatory test to detect IgM antibodies to WNV in the serum. Because IgM seroconversion typically occurs between days 4 and 10 of symptom onset, there is a high probability of initial false-negative testing within the first 8 days after symptom onset. ${ }^{19,20}$ Clinical understanding of this fact is imperative, as an initial negative ELISA does not rule out WNV, and a retest is warranted if clinical suspicion is high. In addition to a high initial false-negative rate with ELISA, there are several other limitations to note. IgM antibodies remain elevated for 1 to 3 months or possibly up to a year in immunocompromised patients. ${ }^{1}$ Due to this, false positives may be present if there was a recent prior infection. Enzyme-linked immunosorbent assay may not distinguish from different flaviviruses, including the yellow fever, dengue, Zika, Japanese encephalitis, and Saint Louis encephalitis viruses. Seropositivity has been estimated in some states, including 1999 data from New York (2.6\%), 2003 data from Nebraska (9.5\%), and 2012-2014 data from Connecticut (8.5\%). ${ }^{21-23}$ Regional variance may be expected, as there also were significant differences in WNV seropositivity between different regions in Nebraska $(P<.001){ }^{23}$

Because ELISA testing for WNV has readily apparent flaws, other tests have been utilized in its diagnosis. The PNRT is the most specific test, and it works by measuring neutralizing antibody titers for different flaviviruses. It has the ability to determine cross-reactivity with other flaviviruses; however, it does not discriminate between a current infection and a prior infection or prior flavivirus vaccine (ie, yellow fever vaccine). Despite this, a positive PNRT can lend credibility to a positive ELISA test and determine specificity for WNV for those with no prior flavivirus exposure. ${ }^{24}$ According to the Centers for Disease Control and Prevention (CDC), this test can be performed by the CDC or in reference laboratories designated by the CDC. ${ }^{3}$ Additionally, some state health laboratories may perform PRNTs.

Viral detection with PCR currently is used to screen blood donations and may be beneficial for immunocompromised patients that lack the ability to form a robust antibody response or if a patient presents early, as PCR works best within the first week of symptom onset. ${ }^{1}$ Tilley et $\mathrm{al}^{25}$ showed that a combination of PCR and ELISA were able to accurately predict $94.2 \%$ of patients (180/191) with documented WNV on a first blood sample compared to $45 \%$ and $58.1 \%$ for only viral detection or ELISA, respectively. Based on costs from a Midwest academic center, antibody detection tests are around $\$ 100$ while PCR may range from
$\$ 500$ to $\$ 1000$ and is only performed in reference laboratories. Although these tests remain in the repertoire for $\mathrm{WNV}$ diagnosis, financial stewardship is important.

If there are symptoms of photophobia, phonophobia, nuchal rigidity, loss of consciousness, or marked personality changes, a lumbar puncture for WNV IgM in the cerebrospinal fluid can be performed. As with most viral infections, cerebrospinal fluid findings normally include an elevated protein and lymphocyte count, but neutrophils may be predominantly elevated if the infection is early in its course. ${ }^{26}$

\section{What are the management options?}

To date, there is no curative treatment for WNV, and management is largely supportive. For WNF, overthe-counter pain medications may be helpful to reduce fever and pain. If more severe disease develops, hospitalization for further supportive care may be needed. ${ }^{27}$ If meningitis or encephalitis is suspected, broad-spectrum antibiotics may need to be started until other common etiologies are ruled out. ${ }^{28}$

\section{How can you prevent WNV infection?}

Disease prevention largely consists of educating the public to avoid heavily wooded areas, especially in areas of high prevalence and during peak months, and to use protective clothing and insect repellant that has been approved by the Environmental Protection Agency. ${ }^{3}$ Insect repellants approved by the Environmental Protection Agency contain ingredients such as DEET (N, N-diethyl-meta-toluamide), picaridin, IR3535 (ethyl butylacetylaminopropionate), and oil of lemon eucalyptus, which have been proven safe and effective. ${ }^{29}$ Patients also can protect their homes by using window screens and promptly repairing screens with holes. ${ }^{3}$

\section{What is the differential diagnosis for WNV?}

The differential diagnosis for fever with generalized maculopapular rash broadly ranges from viral etiologies (eg, WNV, Zika, measles), to tick bites (eg, Rocky Mountain spotted fever, ehrlichiosis), to drug-induced rashes. A detailed patient history inquiring on recent sick contacts, travel (WNV in the Midwest, ehrlichiosis in the Southeast), environmental exposures (ticks, mosquitoes), and new medications (typically 7-10 days after starting) is imperative to narrow the differential. ${ }^{30}$ In addition, the distribution, timing, and clinical characteristics of the rash may aid in diagnosis, along with an appropriately correlated clinical picture. West Nile virus likely will present in the summer in mid central geographic locations and often develops on the trunk and extremities as a blanching, generalized, maculopapular rash around 5 days after symptom onset or with defervescence. ${ }^{1}$

\section{REFERENCES}

1. Petersen LR. Clinical manifestations and diagnosis of West Nile virus infection. UpToDate website. Updated August 7, 2020. 
Accessed April 16, 2021. https://www.uptodate.com/contents /clinical-manifestations-and-diagnosis-of-west-nile-virus -infection?search=clinical-manifestations-and-diagnosis-of-west-nile -virusinfection.\&source=search_result\&selectedTitle $=1 \sim 78 \&$ usage _type=default\&display_rank=1

2. Sampathkumar P. West Nile virus: epidemiology, clinical presentation, diagnosis, and prevention. Mayo Clin Proc. 2003;78:1137-1144.

3. Centers for Disease Control and Prevention. West Nile virus. Updated June 3, 2020. Accessed April 16, 2021. https://www.cdc.gov /westnile/index.html

4. Chuang TW, Hockett CW, Kightlinger L, et al. Landscape-level spatial patterns of West Nile virus risk in the northern Great Plains. Am J Trop Med Hyg. 2012;86:724-731.

5. Wimberly MC, Hildreth MB, Boyte SP, et al. Ecological niche of the 2003 West Nile virus epidemic in the northern great plains of the United States. PLoS One. 2008;3:E3744. doi:10.1371/journal.pone.0003744

6. Centers for Disease Control and Prevention. West Nile virus disease cases reported to CDC by state of residence, 1999-2019. Accessed April 26, 2021. https://www.cdc.gov/westnile/resources/pdfs/data /West-Nile-virus-disease-cases-by-state_1999-2019-P.pdf

7. Hahn MB, Monaghan AJ, Hayden MH, et al. Meteorological conditions associated with increased incidence of West Nile virus disease in the United States, 2004-2012. Am J Trop Med Hyg. 2015;92:1013-1022.

8. Brown CM, DeMaria A Jr. The resurgence of West Nile virus. Ann Intern Med. 2012;157:823-824.

9. Landesman WJ, Allan BF, Langerhans RB, et al. Inter-annual associations between precipitation and human incidence of West Nile virus in the United States. Vector Borne Zoonotic Dis. 2007;7:337-343.

10. Hart J Jr, Tillman G, Kraut MA, et al. West Nile virus neuroinvasive disease: neurological manifestations and prospective longitudinal outcomes. BMC Infect Dis. 2014;14:248.

11. Wu JJ, Huang DB, Tyring SK. West Nile virus rash on the palms and soles of the feet. J Eur Acad Dermatol Venereol. 2006;20:1393-1394.

12. Sejvar J. Clinical manifestations and outcomes of West Nile virus infec tion. Viruses. 2014;6:606-623.

13. Ferguson DD, Gershman K, LeBailly A, et al. Characteristics of the rash associated with West Nile virus fever. Clin Infect Dis. 2005;41:1204-1207.

14. Marszalek R, Chen A, Gjede J. Psoriasiform eruption in the setting of West Nile virus. J Am Acad Dermatol. 2014;70:AB4. doi:10.1016/j. jaad.2014.01.017
15. Shah S, Fite LP, Lane N, et al. Purpura fulminans associated with acute West Nile virus encephalitis. J Clin Virol. 2016;75:1-4.

16. Civen R, Villacorte F, Robles DT, et al. West Nile virus infection in the pediatric population. Pediatr Infect Dis J. 2006;25:75-78.

17. Huhn GD, Dworkin MS. Rash as a prognostic factor in West Nile virus disease. Clin Infect Dis. 2006;43:388-389.

18. Murphy TD, Grandpre J, Novick SL, et al. West Nile virus infection among health-fair participants, Wyoming 2003: assessment of symptoms and risk factors. Vector Borne Zoonotic Dis. 2005;5:246-251.

19. Prince HE, Tobler LH, Lapé-Nixon M, et al. Development and persistence of West Nile virus-specific immunoglobulin M ( $\operatorname{IgM}), \operatorname{Ig} \mathrm{A}$, and IgG in viremic blood donors. J Clin Microbiol. 2005;43:4316-4320.

20. Busch MP, Kleinman SH, Tobler LH, et al.Virus and antibody dynamics in acute West Nile Virus infection. J Infect Dis. 2008;198:984-993.

21. Mostashari F, Bunning ML, Kitsutani PT, et al. Epidemic West Nile encephalitis, New York, 1999: results of a household-based seroepidemiological survey. Lancet. 2001;358:261-264.

22. Cahill ME, Yao Y, Nock D, et al. West Nile virus seroprevalence, Connecticut, USA, 2000-2014. Emerg Infect Dis. 2017;23:708-710.

23. Schweitzer BK, Kramer WL, Sambol AR, et al. Geographic f actors contributing to a high seroprevalence of West Nile virus-specific antibodies in humans following an epidemic. Clin Vaccine Immunol. 2006;13:314-318.

24. Maeda A, Maeda J. Review of diagnostic plaque reduction neutralization tests for flavivirus infection. Vet J. 2013;195:33-40.

25. Tilley PA, Fox JD, Jayaraman GC, et al. Nucleic acid testing for west nile virus RNA in plasma enhances rapid diagnosis of acute infection in symptomatic patients. J Infect Dis. 2006;193:1361-1364.

26. Petersen LR, Brault AC, Nasci RS. West Nile virus: review of the literature. JAMA. 2013;310:308-315.

27. Yu A, Ferenczi E, Moussa K, et al. Clinical spectrum of West Nile virus neuroinvasive disease. Neurohospitalist. 2020;10:43-47.

28. Michaelis M, Kleinschmidt MC, Doerr HW, et al. Minocycline inhibits West Nile virus replication and apoptosis in human neuronal cells. J Antimicrob Chemother. 2007;60:981-986.

29. United State Environmental Protection Agency. Skin-applied repellent ingredients. https://www.epa.gov/insect-repellents/skin -applied-repellent-ingredients. Accessed April 16, 2021.

30. Muzumdar S, Rothe MJ, Grant-Kels JM. The rash with maculopapules and fever in adults. Clin Dermatol. 2019;37:109-118. 